\title{
CONFLICT IN THE LANDSCAPE: A Case Study of the Cultural Values Model
}

\author{
JANET STEPHENSON
}

Public History Review, vol 13, 2006, PP35-52

$\mathrm{O}$ $\mathrm{n}$ the Kapiti Coast of New Zealand's North Island, a four-lane highway is shortly to be constructed through the middle of a waahi tapu, ${ }^{1}$ despite two appeals by the tangata whenua ${ }^{2}$ to the High Court. In the Ahuriri Valley in the South Island, local farmers recently blockaded the road, protesting the action of the Department of Conservation in locking a gate that previously allowed vehicular access further up the valley. In Wellington, community opposition to the inner-city bypass was voiced in street protests and through the courts. At Ngawha, a proposed prison was strongly opposed by some of the tangata whenua because, amongst other things, a taniwha ${ }^{3}$ was associated with the prison site.

Conflicts such as these could be analysed from many perspectives. They could, for example, be examined as conflicts over private property rights versus public interests; as the NIMBY syndrome (not-in-my-back-yard); as natural result of growth and development; or as the outcome of government or big business intervention. But while all of these may be highly relevant, I wish to explore another perspective - that while these conflicts appear to be very different in nature, a common underlying factor is that they arise from differences about what is valued in the landscape. ${ }^{4}$ It is here, I suggest, that the roots of the conflict lie in the failure to recognise and reconcile the multiple values associated with specific places.

Landscapes have played a major role in shaping our multiple and overlapping cultures, and continue to do so. Accordingly, almost every landscape will have some degree of cultural significance. Natural landscapes may be important for their visual splendour, their ecologies, or for the art that they have generated. Lived-in landscapes may contain evidence of early settlements, historic battlefields, or the patterns of different forms of agriculture. An urban landscape may be defined by the street patterns created over a century ago, and may be a storehouse of the collective memories of families and communities. For those who have close associations with particular landscapes, this may arise from the histories, traditions, practices and spiritual beliefs embedded in the landscape. Even visually 'ordinary' landscapes - a field grazed by cows, or a hillside of scrub 
- may hold hidden significance for a farming family, a hapu, or the nation at large. When change or new development threatens a valued landscape, it is thus not just the physical landscape that is being affected but also the collective meanings, memories, and identities that the landscape holds.

In this sense, landscapes are our heritage - they are touchstones of identity, defining who we are as a nation, as iwi and hapu, and as communities. In an era when we are becoming increasingly secure in our national identity, however, landscapes have become a battlefield as they are subjected to rapid and widespread change. In the nineteenth century, we engaged in active conflict over land. Today, we are in regular conflict over landscapes. Our battles are less physical, but are nonetheless fraught.

\section{WIDESPREAD CONCERN}

Landscapes have always been dynamic, in the sense that humans and other forces continually modify their forms. Today, however, change that was once incremental and contained is now rapid and extensive as a result of new technologies and increased investment in development.

Reaction to these changes is not only being vocalised in the streets, the media, and in courtrooms; the upswelling of concern about landscape change is also reflected in a rash of recent conferences in New Zealand. During 2003, for example, two national conferences focused on landscape heritage: one hosted by the NZ Historic Places Trust entitled Heritage Landscapes Think Tank and the other hosted by the Environmental Defence Society entitled Reclaiming Our Heritage: The New Zealand Landscape Conference. In the Waikato, 120 people came together at a workshop entitled The Changing Scene to discuss concerns about the rate and scale of landscape change. The New Zealand Coastal Conference focused on the need to conserve the coast and lakesides in the face of extreme development pressures. The NZ Institute of Landscape Architects' annual conference in April 2005 had the theme of Looking Forward to Heritage Landscapes, and focused on the recognition, protection, interpretation and management of heritage landscapes in New Zealand.

A number of reports have also examined the issues. The Parliamentary Commissioner for the Environment, for example, has published two reports on landscape management. ${ }^{5}$ The Environmental Defence Society explored the 'catastrophic loss' of New Zealand's special places in A Place to Stand: the protection of New Zealand's natural and cultural landscapes. ${ }^{6}$ Reports also emerged from the conferences described above. ${ }^{7}$

What is particularly remarkable about this explosion of interest in 'landscapes as heritage' is the diversity of agencies involved. Equally remarkable is the diversity of participants. I $\mathrm{wi}^{8}$ members, community members, landscape architects, archaeologists, historians, planners, environmentalists, anthropologists, ecologists and many others are coming together to discuss a shared concern that is fundamentally about the loss of culturally valued aspects of the landscape. 
Common themes are emerging in the proceedings and reports. Many relate to specific techniques about how to improve the protection and management of valued landscapes, but lying behind these is a shift in how landscapes are being perceived. One shift is a belief that landscapes are more than their physical features; that located stories, histories and traditions may be as important as the landscape forms. Allied to this is a concern that the local significance of landscapes is often overlooked in development decisions, particularly its role in developing and maintaining local and tribal identity. There is also a widespread unease at landscape assessments which focus on only a single component of landscapes (such as 'naturalness'), and a stated need for approaches that enable an integrated understanding of landscapes' various values and meanings.

\section{THE EVOLVING CONCEPT OF 'LANDSCAPE'}

The widespread interest and concern about this thing called 'landscape' is not just a New Zealand phenomenon. International literature, including various charters and conventions, attests to the growing realisation that landscapes are of fundamental importance to the identities of communities, cultures and nations. The European Landscape Convention, for example, requires each signatory state to 'recognise landscapes in law as an essential component of people's surroundings, an expression of the diversity of their shared cultural and natural heritage, and a foundation of their identity'. ${ }^{9}$ The US International Council for Monuments and Sites' Declaration on Heritage Landscapes describes them as 'the prime expression of the uniqueness of the world and the diversity of its culture'. ${ }^{10}$

Clearly, in these senses, the meaning of landscape has broadened dramatically from the notion of 'scenery' - its primary dictionary definition. But landscape did not always mean 'scenery' in the past, and nor does it appear to mean just 'scenery' any longer. Its evolution in meaning bears some examination.

The use of the word in the English language arises from the sixteenth-century importation of the Dutch word 'landskip'. In its Dutch and German roots, landskip first signified a jurisdictional land unit, ${ }^{11}$ but by the time it was imported into English it was a technical term used by painters, meaning a pictorial representation of a real or imaginary view. ${ }^{12}$ Its representational sense had been influenced by the philosophical division of nature and culture during the Enlightenment. The idea of landscape as scenery was at least partly generated by the conceptual removal of humans from the natural world and the commodification of land, so that it became something to be 'looked over' and represented (in maps and images) rather than just an extension of person and community. ${ }^{13}$

What came to be called 'landscape', therefore, was seen as such because it reminded the viewer of a painted representation. Its artistic meaning became transferred to the visually perceived world by the first generation of tourists during the eigthteenth and early nineteenth centuries, who travelled the world seeking, amongst other things, the experience of the picturesque. ${ }^{14}$ This sense of 
landscape as picture-like scenery has carried through to the present day. The earlier meaning of landscape as a region or a jurisdiction - a politicised meaning closer to the idea of country - has suffered attrition but today is still a parallel dimension of the word. ${ }^{15}$

A further sense of 'landscape' is as a verb, originally meaning the beautifying or redevelopment of a piece of ground so that it resembles an idealised (pictorial) landscape. ${ }^{16}$ From the eighteenth century onwards, early 'landscapers' such as Capability Brown attempted to give physical expression to the principles of the painterly landscape. Developed formally during the nineteenth century, the practice of 'landscaping' later adopted design principles such as unity, repetition, sequence and balance, of harmony and contrast and became the basis of the discipline of landscape architecture.

In the past fifty years, the meaning of landscape has developed even further. The activity of 'landscaping' has moved into new areas of ecology, design and psychology, while landscape painting has evolved to become nonrepresentational. 'Landscape' has become associated with concepts such as naturalness, functional integration, and national and regional identity, as well as retaining its more traditional association with picturesque improvement. ${ }^{17}$

'Landscape' is also increasingly used in a variety of fields to describe particular disciplinary approaches. While it has long been of interest to geographers and archaeologists, it has been adopted in recent decades by a wider variety of disciplines, and is used variously by them to reflect their particular disciplinary interests in a spatial context (such as 'landscape ecology', 'landscape history').

Of particular interest, however, is how it is now being used by individuals and groups to express concepts of place and belonging. Literature in this field suggests that people become collectively attached to the particular landscapes with which they associate. In New Zealand, for example, a Maori researcher found that within Ngai Tahu the majority of interviewees used 'landscape' to describe a totality of meaning relating to their ancestral lands, including genealogical connections, place names, identity, spirituality and sustenance. ${ }^{18}$ Community residents also use 'landscape' to encompass a wide range of values and meanings that human meanings in the environment. A study in Bannockburn, Central Otago, for example, showed that local people not only valued the visible physical landscape, but also its histories and stories, genealogical connections, sense of place, and the traditions, practices and processes particular to that landscape. $^{19}$

As studies show, individual and group identity can be strongly enmeshed with landscape and its cultural values. For those with a long association with a particular place, the landscape can become imbued with ancestral associations. ${ }^{20}$ Custom, ritual and myth can strengthen attachment to place by reaffirming the enduring relationship between people and place. ${ }^{21}$ Names, songs and stories also reflect community relationships with landscapes, providing continuity with the past, and linking meanings to places. The environment, and the events and 
practices that have occurred within it, create and affirm community and cultural identities. ${ }^{22}$ Landscape is not only personal and tribal history made visible, but also an ongoing reinforcement of identity, spirituality and sustenance. ${ }^{23}$ Even over a short period of acquaintance, the qualities of a landscape can generate feelings of belonging, rootedness and familiarity. In the Bannockburn study, for example, several interviewees referred to a sense of attachment to the landscape even when they had not been long resident. ${ }^{24}$

These studies suggest that 'landscape' can include the material and nonmaterial aspects of a physical area, its human and natural aspects, and its mythological and cognitive aspects. Landscape can be a human-modified artefact, a resource for development, or defined by its ecological, cultural, economic or social significance. Landscape can mean topography, nature, habitat and the functional processes of the environment. It can mean the aesthetic and subjective impressions of a place, including its poetic, ideological and symbolic meanings. People draw on their knowledge and experience of the landscape to give meaning, certainty and significance to their lives. As Relph suggests, for many people a profound attachment to place may be 'as necessary, and perhaps as unavoidable, as close relationships with people'. ${ }^{25}$

This was reinforced by research undertaken by the writer in Bannockburn and Akaroa, where interviews were carried out with residents and tangata whenua as to the significance of the surrounding landscape ${ }^{26}$ Both case studies revealed that landscape values are not limited to the physical forms of landscapes (landforms, vegetation, structures), but also relate to contemporary and past practices, and to relationships with the landscape that have evolved over time. Although the visual and experiential aspects of the landscape are certainly important, most community members and tribal members associated with the area also highly valued the way in which landscape holds and transmits the past. Additionally, the reported experience of landscape was seamless in the sense that values were indivisible; the visual enjoyment of the bush on the hillside was integral with the ability to walk though it, the knowledge of its ecological values, the food that it could produce, and historic events that had led to its preservation. The physical, active and meaning-filled components of landscape interacted to generate a landscape of dynamic significance - not a watercolour painting to be observed, but a living and incrementally changing phenomenon from which people drew emotional sustenance and cultural meaning.

\section{WHY IS THIS OCCURRING?}

Just why 'landscape' is being so widely adopted and adapted bears consideration. Its increased use by disciplines has been widely commented on in the literature, with a common consensus that the concept offers a broad, expansive and inclusive approach. ${ }^{27}$ Less clear is why it has been adapted by insiders, such as tangata whenua and other community members (who would not necessarily be aware of how disciplines use landscape concepts). I suggest that it may be driven at least partly by a reaction to the rate of change. While change 
was slow and predictable, insiders possibly had no need for a word to capture the meaning and significance of their surroundings - such values were a given - and the original sense of 'landscape as scenery' was adequate to convey its value to outsiders. Recent rapid change, however, has resulted in dislocation between insiders and their landscapes, loss of local distinctiveness, and loss of the meaning and significance of particular places. The gradual realisation of the nature of these losses, and the desire to limit the effects of change, may have contributed to the adoption of the word 'landscape' to refer to rafts of cultural values associated with people's surroundings.

The reason for this may be that these broader meanings are not captured by the words or concepts that are in common use by decision-makers and change agents. The closest equivalent to 'landscape', for example, is 'environment', the catchword of global environmental awareness. 'Environment' is frequently used in planning contexts, and is used to refer primarily to natural and physical features, locale and setting. It has an abstract but rational meaning, and may have been less adaptable to reflecting human values due to its emphasis on natural systems. 'Landscape', on the other hand, has proved itself sufficiently adaptable that both communities and disciplines now use the term to encompass a range of expressions of cultural significance. In the absence of any other suitable term, 'landscape' has grown to fill a need for a legitimate source for expression for located cultural significance.

\section{THE LEGISLATIVE LANDSCAPE}

Formal methods of attributing significance to landscape have not kept abreast of the emergence of its rich and complex meaning. A fundamental cause of the conflict over landscapes, I believe, is that the currently legitimised categories of landscape value largely fail to capture their complex and dynamic significance their cultural values.

The landscape of New Zealand's international image is the landscape of 'naturalness'. This landscape is one of mountains, coastlines and indigenous forests, apparently untarnished by humans. This is underpinned by a strong commitment at a national level to the preservation of these 'natural' values through national policies (such as the NZ Biodiversity Strategy), institutions (including the Department of Conservation) and legislation (for example, Conservation Act 1987, Resource Management Act 1991). At this level, the importance of 'naturalness' in landscapes is strongly promoted, under various guises such as ecological values or 'natural character'. The focus here is recognition of the material characteristics of land and biota.

The historic and cultural significance of landscapes is a poorer cousin to natural values. Of the two primary avenues for the recognition and protection of these values - the Historic Places Act 1993 (HPA) and Resource Management Act 1991 (RMA) - none fits comfortably with the range of landscape values discussed above. The HPA, for example, falls short of recognising landscape heritage in this broad sense. The Historic Places Register can include historic 
places and areas: a 'historic place' being any land that forms part of the historic and cultural heritage of New Zealand, and a 'historic area' containing an interrelated group of historic places. In practice, the Historic Places Register is largely a catalogue of around 6000 buildings and clusters of buildings, together with some archaeological sites. It is firmly focused on the physical components of heritage, with little leeway to recognise on the dynamics of cultural values in landscapes. The HPA's provision for waahi tapu and waahi tapu areas (places sacred to Maori in the traditional, spiritual, religious, ritual, or mythological sense) goes some way towards recognising cultural significance that does not necessarily have a visible counterpart, but is inappropriate for recognition of sites that are culturally significant yet not sacred. So far, the HPA has not been used to formally recognise landscape significance in its broad sense, but rather to identify specific parts that are of value to specific groups. Its provisions may not be appropriate for this purpose in any case, given that it was devised at a time when the heritage landscapes concept did not enjoy the widespread acceptance it does today.

The other primary avenue for protection of valued landscapes is provided by the Resource Management Act. As noted earlier, the RMA gives high priority to preserving 'naturalness' in coastal areas, lakes and river margins, and landscapes. ${ }^{28}$ Case law has made it clear that 'landscape' in this context can include both physical and perceptual attributes, demonstrated by layers of association and meaning, and different cultural values attributed over time ${ }^{29}$. The criteria for determining 'outstanding natural landscapes' should focus largely on the physical characteristics of a landscape, but also should include its historical associations and its value to tangata whenua. ${ }^{30}$ In light of the range of cultural values in landscapes discussed above, this sounds helpful. In practice, however, landscapes need to have strong natural values before they are in the running to be recognised as being landscapes of outstanding value that require protection.

Other values of landscape are accorded even less significance under the RMA. While it encourages councils to recognise and protect historic heritage, this is largely addressed in practice through schedules of historic structures and archaeological sites. Maori relationships with resources are similarly dealt with at a site-specific level rather than a landscape level.

Overall, the legislation seeks to identify and, where necessary, protect certain components of the landscape, but fails to integrate those components into an understanding of the whole. The RMA, for example, sets up its matters of national importance largely according to disciplinary specialties. Landscape architects define natural character and outstanding landscapes; ecologists define significant habitats and vegetation; historians, archaeologists and conservation architects focus on historic heritage, and tangata whenua are consulted on culturally significant sites. The legislation encourages 'silo' thinking, and reinforces a divided approach to recognising and managing landscape values.

There is also a notable absence of formal recognition of the role of landscapes in reflecting and maintaining local cultural diversity and identity, 
except, to some extent, in relation to iwi and hapu. ${ }^{31}$ Formal methods of recognition predominantly focus on aspects of the visible and physical environment that can be assessed by disciplinary specialists rather than the unseen connections between people and place. Yet it is at this level that landscape conflicts often erupt.

THE POTENTIAL FOR A MORE INTEGRATEd UNDERSTANDING OF LANDSCAPE VALUES The problem of silo approaches to landscape has been discussed internationally within a number of landscape-related disciplines. McGlade suggests that the heart of the problem is the "systematic fragmentation of separate specialist observations which are then "incorporated" into a synthetic reconstruction of the cultural environment'. ${ }^{32}$ This can be seen, for example, where predetermined categories of value are used to determine cultural significance. In practice, it is often difficult to divide human responses into terms such as 'aesthetic' or 'historic' value, and those assessing landscape value may end up fitting views to words rather than vice versa. ${ }^{33}$ Values which do not 'fit' the classification system or which arise from interactions between different aspects of the same landscape can be overlooked or divided between categories.

Many assessment methods also omit understandings and values of those who are attached to a particular landscape. Methods involving communities of interest have been developed, ${ }^{34}$ but expert approaches based on the contribution of particular academic disciplines still dominate. These may offer specialist interpretations of indigenous or community values, but may not necessarily convey their distinctive significance to insiders, which 'resides simultaneously in the tangible forms of the landscape and in the minds of its individuals' ${ }^{35}$

Yet the concept of 'landscape' is also being increasingly lauded as a concept which has the potential to diffuse the conventional boundaries between disciplines and generate new forms of knowledge. Its potential for transdisciplinary synthesis is noted by writers in a number of fields. ${ }^{36}$ As a concept, these authors suggest, 'landscape' potentially allows multiple investigators to pursue different research topics, yet contribute collectively to a more comprehensive understanding of spatial, temporal, ecological and cognitive concepts. It offers a unifying theme within which to consider the relative contributions of many disciplines, and achieve a holistic understanding of landscape values. It also provides an opportunity for collective ventures between disciplines and communities.

Landscape's unifying potential, however, is as yet largely unexplored. The lack of common ground between disciplines is one barrier, but a more fundamental barrier, I suggest, is that the concept of landscape has a confusing duality: it is both substantive and conceptual.

In its substantive sense, landscape has a bundle of meanings defined in various ways by disciplines and associated communities. Like a mirrored ball, it may reflect a different landscape image depending on the interest or world-view of the viewer. The reflected image may be a physical object, a perception, a 
tradition, a relationship, or any of the other components of landscape discussed above. In this sense, landscape is something to be looked at, analysed, understood, valued or managed, from any one of a myriad points of view. These different facets of landscape are summarised in Figure 1.

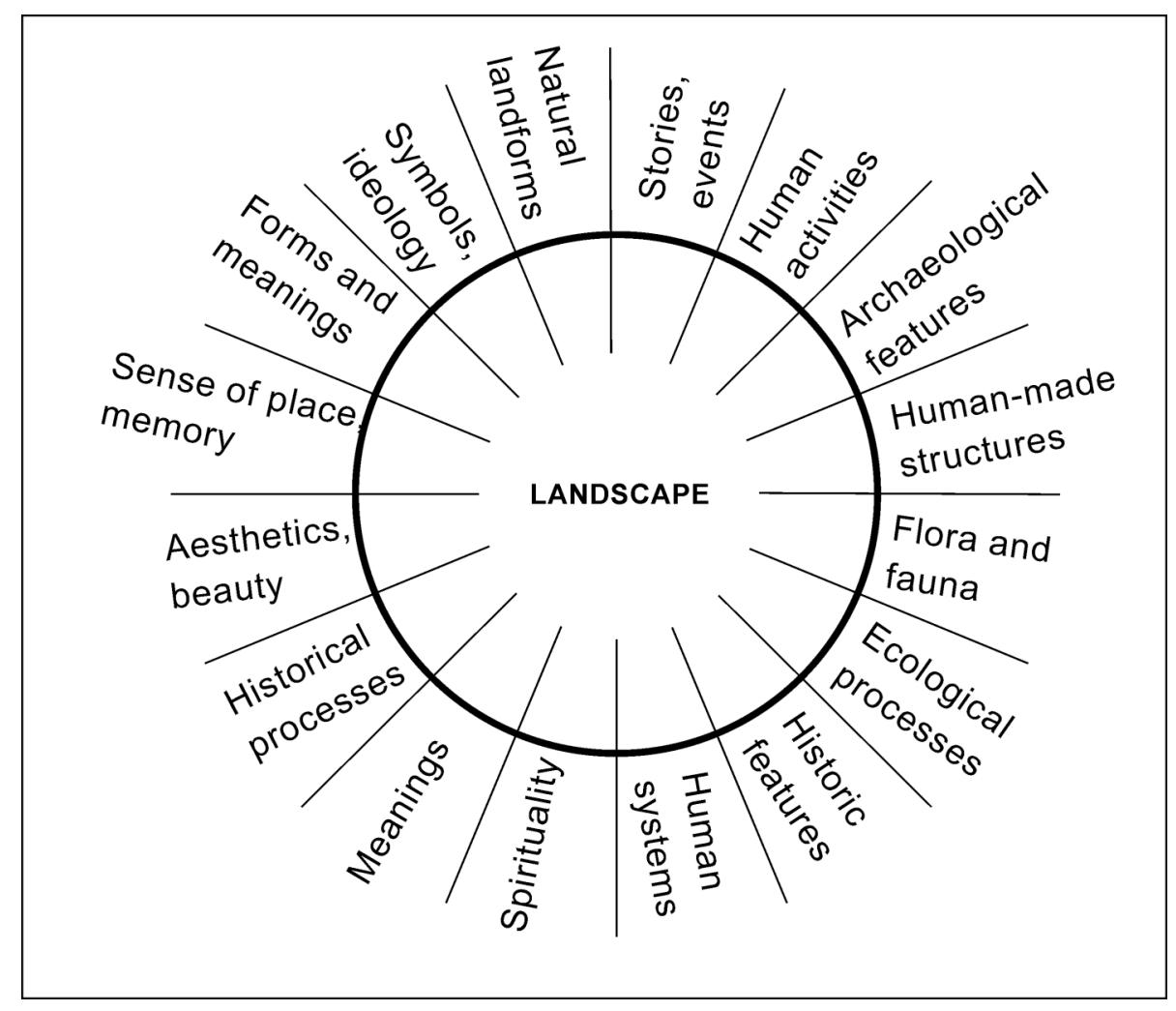

FIGURE 1: The range of values and significance imputed by both disciplines and those with particular associations with landscape. While particular disciplines or agencies may have an interest in only one or two of each of these value clusters, members of associated communities are likely to hold many of these values in a relatively unbounded fashion.

Discipline-based landscape assessments generally consider one or two of these substantive aspects of landscape. The resulting information stands alone as a fraction - informative in its own right, but not representative of the totality of landscape values. This approach is represented in our legislative approach to landscape recognition and protection.

As a concept, landscape is more akin to an umbrella; a common idea that can be shared by both disciplines and communities. But while this offers exciting possibilities for cross-fertilisation of theory and practice, the struts that define the shape, strength and unity of the umbrella are largely unformed. In other words, the concept lacks an integrated theoretical and analytical framework. To extend the metaphor: while disciplines may place themselves partly in the shade of the umbrella, they do not necessarily know its overall form. 


\section{A Proposed Conceptual Framework}

A conceptual framework needs to be founded in the substantive landscape - the multiple versions of landscape seen in the mirrored ball. It needs to take into account all of the ways of understanding and valuing landscape. The Cultural Values Model, described below, was developed on this basis, ${ }^{37}$ informed by an analysis of the landscape-related values expressed by communities in two case studies, and the literature of relevant disciplines. This was enriched by a review of existing 'holistic' models of landscape or space that had been proffered from within a variety of disciplines over the past 50 years. ${ }^{38}$

The strong synergies that emerged from this analysis led to a model of landscape value that consists of three basic components - forms, practices and relationships. In Figure 2, the 'value silos' from Figure 1 are regrouped according to these three components.

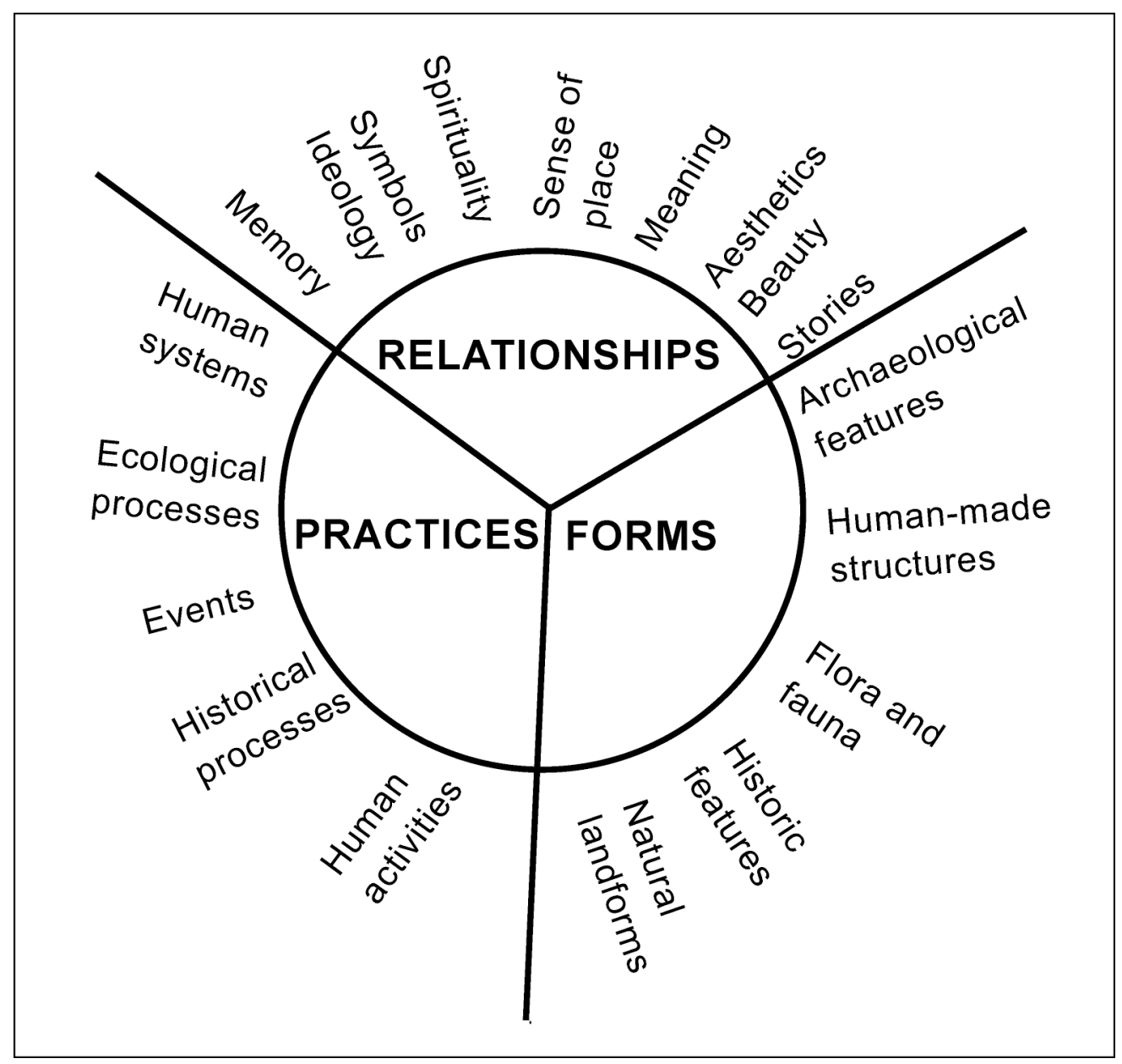

FIGURE 2: Landscape values sorted according to the three basic components of forms, relationships and practices. 
The term forms captures the physical, tangible or objective aspects of landscape. It includes both natural features (including landforms and vegetation) and forms created by or resulting from human intervention (such as structures and gardens). The term is consciously inclusive of both cultural and natural forms.

Practices captures activities and processes that are associated with a landscape. Both human practices (actions, events and traditions) and natural processes (geological, ecological) are potentially culturally important. The term 'practices' encompasses both human practices and natural processes.

The term relationship is used to encompass the third group of concepts. Human relationships with landscapes are the generators of meaning and significance. This can be represented in many ways including spirituality, myth, sense of place, naming, stories and through arts such as literature and song. In some cultures, people may be directly related to landscapes through genealogical descent, and parts of the landscape may be genealogically related to other parts (for example, within Maori culture). The term can also encompass ecological and functional relationships between aspects of natural systems.

Using these concepts, a landscape model emerges that presents the landscape as a continually interacting matrix of forms, practices and relationships. Practices create forms; forms determine relationships, and relationships determine practices. Each part influences the other, is inseparable from the other, and is in continual dynamic interchange. This dynamism can be represented as in Figure 3.

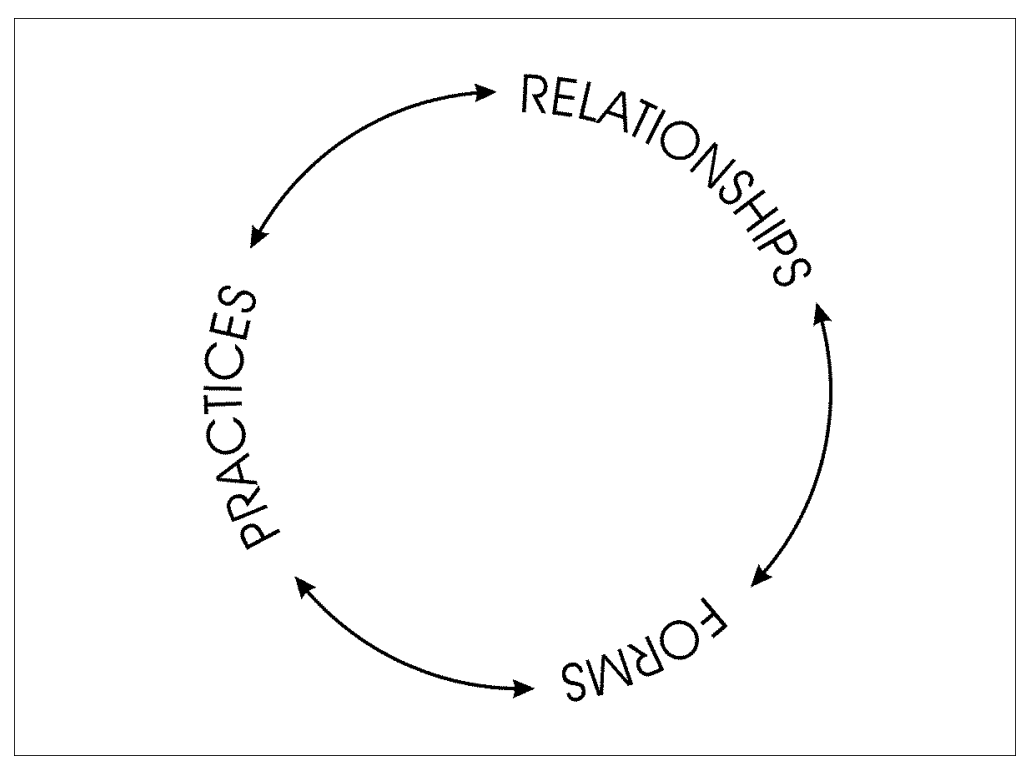

FIGURE 3: The dynamic interaction of forms, practices and relationships.

As well as being dynamic, however, landscapes are also temporal. They represent both the past and the present simultaneously. Developed further, the 
model shows landscape as a continuum, bearing within it the forms, relationships and practices of the past that have created the present (Figure 4).

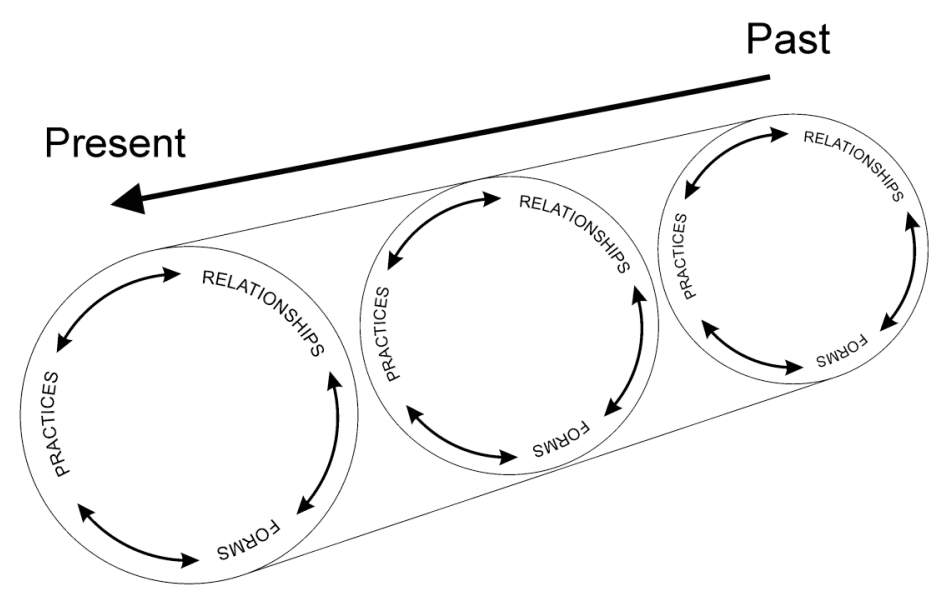

FIGURE 4: Cultural Values Model

These concepts form the basis of the Cultural Values Model. The model suggests that landscapes can be understood in an integrated way through consideration of forms, relationships and practices; the dynamic interactions between these; and the dimension of time. Aspects of landscape that are considered to be 'valuable' may arise from all or any of these. Accordingly, it is necessary to take account of all of these landscape components to achieve an understanding of cultural values as a whole.

Another way of considering landscape values is according to whether they arise from an immediate response to the physical environment (such as an aesthetic response), or whether they arise from relationships and understandings of the landscape that arise from its temporality (like historic events or practices). To describe this distinction, the terms surface values and embedded values are proposed. Surface values are those generated by a purely visual or sensory response to the physical landscape, while embedded values arise from the continuity of past forms, practices and relationships. This is shown diagrammatically in Figure 5. 


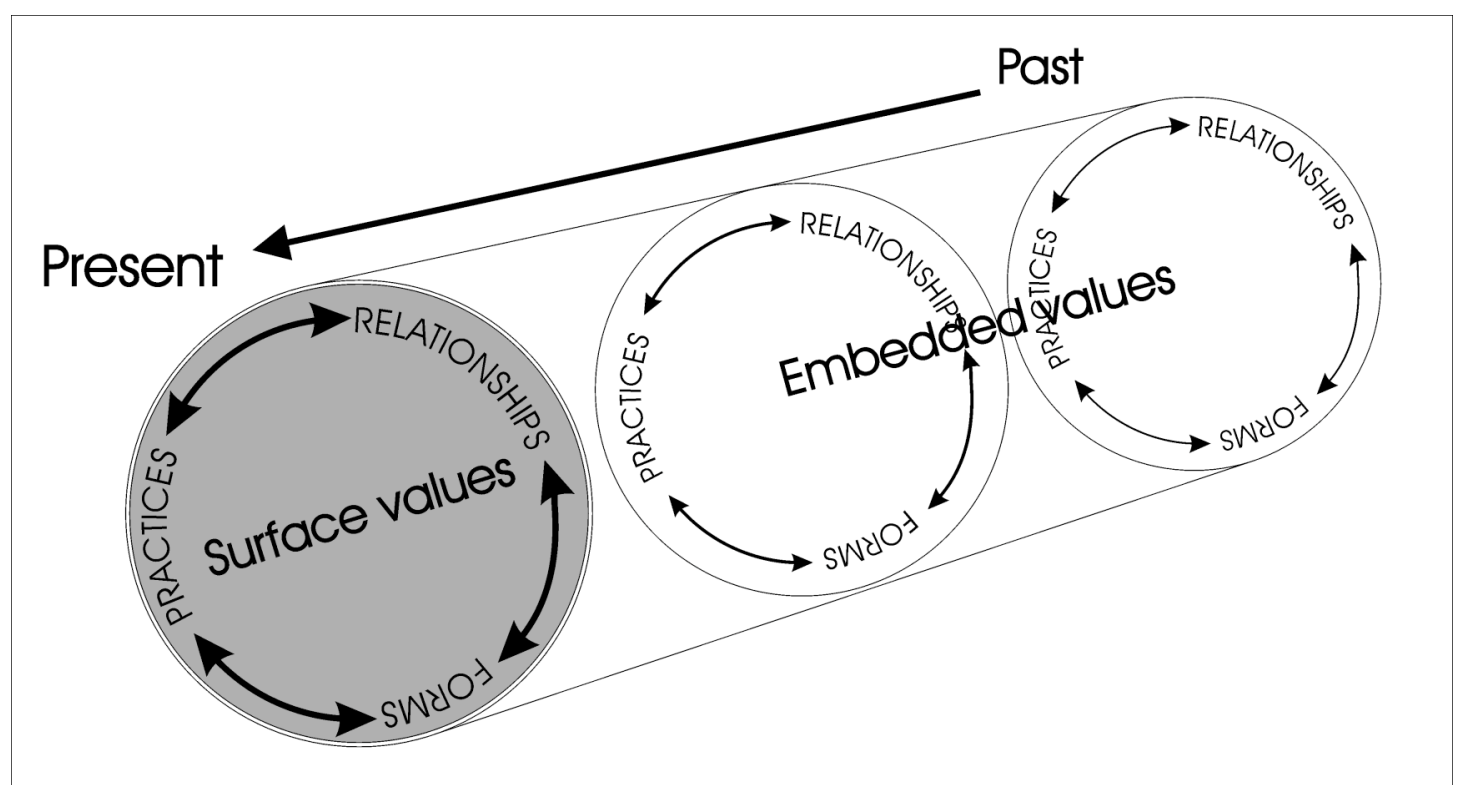

FIGURE 5: Using the Cultural Values Model to portray surface and embedded values.

The model sheds some light on the emerging debate in New Zealand regarding landscape significance discussed earlier. The NZHPT 'Heritage Landscapes Think Tank', referred to earlier, focused on forms, relationships and practices of the past as significant generators of value (the embedded landscape). The EDS 'Reclaiming Our Heritage' conference focused more on the surface landscape - largely on natural forms, and their associated relationships and practices. Integrating these considerations can lead to a more holistic appreciation of the landscape as a whole (as was beginning to emerge at the NZILA 'Looking Forward to Heritage Landscapes' conference in 2005). The Cultural Values Model also has the potential to assist in understanding some of the roots of conflict in the landscape.

\section{UNDERSTANDING CONFLICT IN THE LANDSCAPE}

As the model makes clear, a landscape analysis that focuses on a single component of value will not be representative of landscape significance as a whole. A landscape assessment of the natural and aesthetic values of the landscapes, for example, is largely an analysis of the surface landscape, and largely limited to its forms. A survey of archaeological sites is largely a compilation of embedded forms; such a survey alone will not be informative as to the practices and relationships of the embedded landscape, and would therefore offer only a limited understanding of the landscape values as a whole.

Figure 6 indicates the contribution of some of the more common forms of landscape assessment to an understanding of the landscape as a whole, as used in decision-making frameworks under the legislation discussed previously. These 
are largely consistent with the main silos of 'landscape' conveyed in New Zealand legislation: ecological values, natural values, aesthetic values, historic and archaeological values, and sites of significance to iwi.

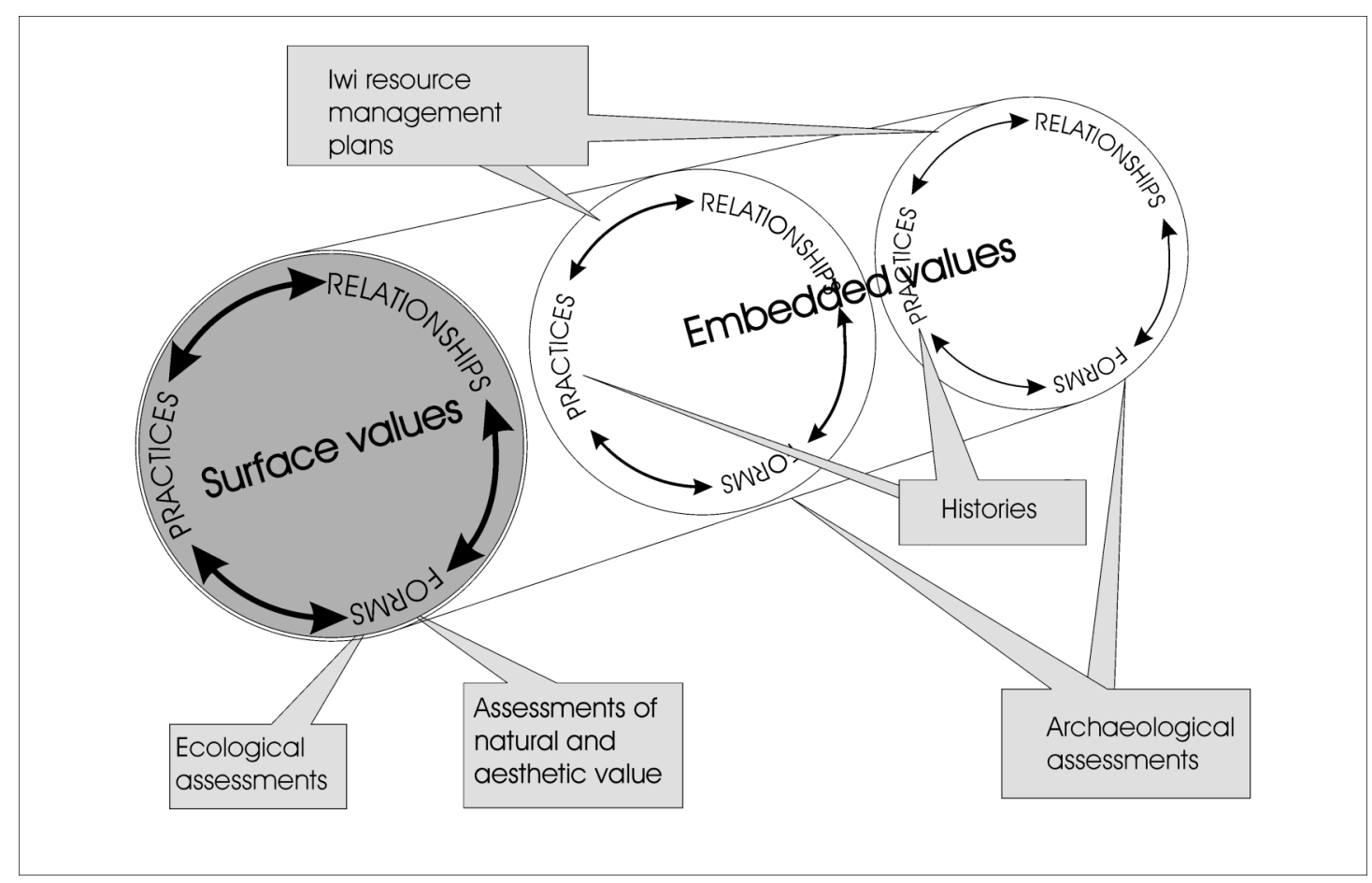

FIGURE 6: Using the Cultural Values Model to indicate the relative contribution of some of the more common forms of landscape assessment to an understanding of the landscape as a whole.

As Figure 6 makes clear, individual disciplines can make a contribution toward appreciating certain aspects of the landscape, but none draw these together as a whole. Additionally, a number of key aspects are not addressed in these more commonly used forms of landscape assessment - those by landscape architects (typically covering aesthetic and natural values), ecological assessments, and archaeological assessments). Common omissions include the valued practices and relationships associated with the surface and embedded landscapes - local histories and (for Maori) iwi management plans can assist but not always available. Additionally, most assessments rely on expert reports from 'outsiders' rather than find means of conveying the values that are held by the people who interact most closely with that landscape. Missing also is a formal way of accounting for the dynamic linkages between forms, practices and relationships. Instead, value assessments tend to focus on particular facets of landscape, while ignoring or giving limited attention to other facets or how these may enrich one another. Such partial understandings of value, I suggest, lie behind many landscape conflicts, particularly where the significance of one of these parts is elevated over others. 


\section{LANDSCAPE WARS REVISITED}

The 'landscape wars' outlined in the opening paragraph of this article can be better understood in light of this discussion. The approach taken by the Court relating to the waahi tapu area on the Kapiti coast, for example, was to focus on trying to establish the existence and significance of certain forms in the landscape, as opposed to a more integrated appreciation of the dynamics of relationships and practices with that particular landscape. The waahi tapu area includes an urupa ${ }^{39}$ which is still used, together with a more extensive area that appears to be 'natural' - grass, scrub and a swamp - but is sacred for a number of interrelated reasons, not all of which have a physical counterpart. The proposed highway is to pass through this latter area. The Environment Court's analysis of the significance of the waahi tapu area revolved around the degree of evidence that existed for human burials and buried taonga ${ }^{40}$ in the line of the proposed road. Cursory attention was paid to the dynamic and powerful relationships between tangata whenua and this place, and the case turned on the levels of proof that material remains existed beneath the ground surface. ${ }^{41}$

Even though a very different set of circumstances exist, the protest at Ahuriri Valley can also be related to a lack of provision for the relationships and practices of local people with the landscape. When the Department of Conservation (DOC) purchased Birchwood Station in the Ahuiriri Valley, a gate which had previously been able to be driven through (with the owner's permission) was locked, preventing vehicular access into the upper reaches of the valley. Local farmers staged a dramatic protest, disrupting the formal opening. ${ }^{42}$ While DOC had legitimate reasons for locking the gate, the locals who had contributed to the construction and maintenance of huts further up the valley, and who had traditionally used the road for access to the huts and hunting areas, considered it an affront. Local people's relationships and practices had not been given the recognition that they considered was due, and conflict resulted.

The model can also help understand other landscape conflicts. Protest about the inner-city bypass in Wellington, for example, can be understood as concern not only about the loss of the individual historic buildings that stood in its way, but a loss of a whole portion of traditional townscape, and the stories, memories and meanings that it held for people. The taniwha at Ngawha can be seen as an embedded relationship in that landscape. Cultural difference and the lack of a physical form made it more dispensable than values that lie within western scientific concepts of the objectively accountable, such as the presence of rare flora and fauna.

Taking a 'landscape' perspective on these issues is only one way of considering them, and many other factors also come into play in seeking a less conflict-ridden approach to change and development. However, the integrated framework offered by the Cultural Values Model offers some useful insights into why conflicts occur, how landscape values are interrelated, and the range of issues that might need to be considered to work towards a solution. 


\section{Conclusion}

The distinctive set of values that relate to a particular landscape exist regardless of the ownership structure of the land from which it is composed and can be impacted on by new development and new uses. Such changes can affect community, tribal and national identity, dilute local distinctiveness and generate disjunctions between people and the past. The landscape wars suggest that these matters are of great concern to many, and that it is important that the process of change is informed by an awareness of its implications for these less tangible phenomena.

Decision-making processes relating to new developments commonly incorporate some specialist reports on selected aspects of the landscape, but are far less accomplished at recognising the distinctive cultural heritage that arises from the close interactions between people and their landscapes. To achieve better management of the multiple interests in landscape, it is necessary to move beyond 'silo' thinking, and to be inclusive of values that currently fall outside of standardised assessment methods.

Better management entails acceptance of values expressed in many forms qualitative and quantitative, subjective and objective, tangible and intangible, secular and spiritual. It involves recognising that landscapes are places where the values of different cultures meet and overlap, so that legitimacy must be given to different cultural world-views. It involves realisation that a single aspect of a landscape may be valued for many different reasons, including both communityexpressed values and discipline-expressed values, and an acceptance that all of these may be valid. Above all, it requires an integrated understanding of the significant forms, relationships and practices of a landscape, and how these interact to create dynamic and meaningful spaces. In this way, landscape can be appreciated in its duality - in both its substantive form of multiple perspectives, and in its conceptual form as a unifier of knowledge and values.

\section{ENDNOTES}

\footnotetext{
${ }_{1}^{1}$ A sacred place to Maori, the indigenous people of Aotearoa/New Zealand.

${ }^{2}$ Local people, literally 'people of the land'.

${ }^{3}$ Water monster.

${ }^{4}$ The totality of these values could be described in terms other than 'landscape', but its increasing use as a descriptor for bundles of located values makes it a prime concept in this regard.

${ }^{5}$ Parliamentary Commissioner for the Environment, Managing Change in Paradise: Sustainable Development in Peri-urban Areas. Parliamentary Commissioner for the Environment, Wellington, 2001; Parliamentary Commissioner for the Environment, Superb or Suburb? International case studies in management of icon landscapes. Parliamentary Commissioner for the Environment, Wellington, 2003.

${ }^{6}$ R. Peart, 'A Place to Stand: the protection of New Zealand's natural and cultural landscapes',

Environmental Defence Society, Auckland, 2004.

${ }^{7}$ Janet Stephenson, 'Heritage Landscapes Think Tank: Report on Proceedings. NZ Historic Places Trust', Wellington, 2003; Environmental Defence Society, Reclaiming Our Heritage: The New Zealand Landscape Conference, Environmental Defence Society, Auckland, 2003; Advisory Committee for Regional Environment and NZ Institute of Landscape Architects, The Changing Scene: Report of a workshop on landscape management, Environment Waikato, Hamilton, 2004.

${ }^{8}$ Tribe, tribal.

${ }^{9}$ Council of Europe, European Landscape Convention in US/ICOMOS Scientific Journal 2000, 2(1), pp8892.
} 
${ }^{10}$ ICOMOS USA, Natchitoches Declaration on Heritage Landscapes. United States Committee, International Council on Monuments and Sites, www.icomos.org/usicomos, accessed 3.12.2004.

${ }_{11}^{11}$ Simon Schama, Landscape and Memory, Fontana Press, London, 1996.

${ }^{12}$ E. Hirsch, 'Landscape: Between Place and Space', in The Anthropology of Landscape: Perspectives on Place and Space E. Hirsch and M. O'Hanlon (eds), Clarendon Press, Oxford, 1995.

${ }^{13}$ B. Bender, 'Landscape and Politics', in The Material Culture Reader, V. Buchli (ed), Berg , Oxford and New York, 2002; S.C. Bourassa, The Aesthetics of Landscape, Belhaven Press, London and New York, 1991; C.A. Tilley, A Phenomenology of Landscape, Berg, Oxford, 1994.

${ }^{14}$ Hirsch, op cit; M. Andrews, The Search for the Picturesque: Landscape, Aesthetics and Tourism in Britain 1760-1800, Scolar Press, Aldershot, 1989.

${ }^{15}$ Schama, op cit, p196.; K.R. Olwig, Landscape, Nature and the Body Politic.,University of Wisconsin Press, Madison, 2002.

${ }^{16}$ J.B. Jackson, Discovering the Vernacular Landscape, Yale University Press, New Haven and London, 1984.

${ }^{17}$ S.R. Swaffield, 'Roles and meanings of "landscape"', PhD thesis, Resource Studies, Lincoln University, Canterbury, 1991.

${ }^{18}$ K.J. Russell, 'Landscape: Perceptions of Kai Tahu i mua, aianei, a muri ake', PhD thesis, Anthropology, Otago University, Dunedin, 2000.

19 J. Stephenson, H. Bauchop and P. Petchey, Bannockburn Heritage Landscape Study, Department of Conservation/ Te Papa Atawhai, Wellington, 2004.

${ }^{20}$ C. Smith, 'Ancestors, place and people: social landscapes in Aboriginal Australia', in The Archaeology and Anthropology of Landscape: Shaping your landscape, P. J. Ucko and R. Layton (eds), Routledge, London and New York, 1999; J. Klaricich, 'The Land History of Whiria', (unpublished) 2001; Maori Heritage Council, Submission to the Historic Heritage Management Review, NZ Historic Places Trust, Wellington, 1998.

${ }^{21}$ E. Relph, Place and Placelessness, Pion, London, 1976.

${ }^{22}$ W. P. Stewart, D. Liebert et al, 'Community identities as visions for landscape change', Landscape and Urban Planning, 2004, 69 (2-3), pp315-334.

${ }^{23}$ Russell, op cit.

${ }^{24}$ Stephenson, Bauchop et al, op cit.

${ }^{25}$ Relph, op cit, p41.

${ }^{26} \mathrm{~J}$. Stephenson, 'Values in Space and Time: A framework for understanding and linking multiple cultural values in landscapes', PhD thesis, Geography, Otago University, Dunedin, 2005.

${ }^{27}$ See for example P. Jackson, Maps of Meaning, Routledge, London, New York, 1989; P. Groth and T. W. Bressi (eds), Understanding Ordinary Landscapes, Yale University Press, New Haven and London, 1997; S. Stoddart (ed), Landscapes from Antiquity, Antiquity Publications Ltd, Cambridge, 2000; T.S. Terkenli, 'Towards a theory of the landscape: the Aegean landscape as a cultural image', Landscape and Urban Planning, 2001, no 57, pp197-208.

${ }_{29}^{28}$ Section 6 Resource Management Act 1991.

${ }^{29}$ NZ Marine Hatcheries Ltd v Marlborough DC W129/97, 3 NZED 152.

${ }^{30}$ Wakatipu Environmental Society Inc v Queenstown Lakes District Council C180/99 5 NZED 85.

${ }^{31}$ Sub-tribes.

32 J. McGlade, 'Archaeology and the evolution of cultural landscapes: towards an interdisciplinary research agenda', in P. J. Ucko and R. Layton (eds), The Archaeology and Anthropology of Landscape: Shaping your landscape, Routledge, London and New York, 1999, p467.

${ }_{33}$ M. Walker, 'Social Value: Meaning and Action', in Sandy Blair, People's Places: Identifying and Assessing Social Value for Communities, Australian Heritage Commission, Melbourne, 1993.

${ }^{34}$ For example R. Mason, 'Assessing Values in Conservation Planning', in M. de la Torre (ed), Assessing the Values of Cultural Heritage: Research Report, The Getty Institute, Los Angeles, 2002, pp5-30; Blair, op cit; J. Domicelj and S. Domicelj (eds), A Sense of Place? A conversation in three cultures, Australian Heritage Commission, Canberra, 1990.

${ }_{35} \mathrm{~J}$. Allison, 'Self-determination in cultural resource management: indigenous peoples' interpretation of history and of places and landscapes', in P. J. Ucko and R. Layton (eds), The Archaeology and Anthropology of Landscape, Routledge, London and New York, 1999, p280.

${ }^{36}$ For example McGlade, op cit; Terkenli, op cit; C.L. Crumley and W. H. Marquardt, 'Landscape: A unifying concept in regional analysis', in K. M. S. Allen, Stanton W. Green and Ezra B.W. Zubrow (eds), Interpreting Space: GIS and Archaeology, Taylor \& Francis, London and New York, 1990; B. Tress and G. Tress, 'Capitalising on multiplicity: a transdisciplinary systems approach to landscape research', Landscape and Urban Planning, no 57, 2001,pp143-157.

${ }^{37}$ Stephenson, op cit.

${ }^{38}$ Key references here include K. Lynch, The Image of the City, Technology Press, Cambridge, Mass., 1960; Relph, op cit; H. Lefebvre, The Production of Space, Blackwell, Oxford, 1991; A.W. Spirn, The Language of Landscape, Yale University Press, New Haven and London, 1998; T. Darvill, 'The historic environment, historic landscapes, and space-time-action models in landscape archaeology', in P. J. Ucko and R. Layton (eds), The Archaeology and Anthropology of Landscape: Shaping your landscape, Routledge, London and New York, 1999; K. Soini, 'Exploring human dimensions of multifunctional landscapes through mapping and map-making', Landscape and Urban Planning, no 57, 2001, pp225-239; Terkenli, op cit. 
Public History Review, vol 13, 2006

${ }^{39}$ Cemetery.

${ }^{40}$ Treasures.

${ }^{41}$ Te Runanga o Ati Awa ki Whakarongotai and Takamore Trustees v. Kapiti District Council W050/2003 8 NZED 771.

${ }^{42}$ Otago Daily Times, 9 March 2005. 